\title{
TABLE ERRATA
}

528.-I. S. GRadShteyn \& I. M. Ryzhik, Tables of Integrals, Series, and Products, 4th ed., Academic Press, New York, 1965.

On page 1015 the hypergeometric function in formula 8.812 should be

$$
F\left(\frac{m-n}{2}, \frac{m-n+1}{2} ; \frac{1}{2}-n ; \frac{1}{x^{2}}\right) \text {. }
$$

School of Chemical Sciences

ANN SCHERZINGER

University of Illinois

Urbana, Illinois 61801

EDITORIAL NOTE: For previous notices of errata in this edition see Math. Comp., v. 22, 1968, pp. 903-907, MTE 428; v. 23, 1969, pp. 468-469, MTE 437; ibid., pp. 891-892, MTE 446; v. 25, 1971, p. 200, MTE 473; v. 26, 1972, p. 305, MTE 486; ibid., p. 599, MTE 492; v. 27, 1973, pp. 451-452, MTE 503.

529.- Milton Abramowitz \& Irene A. Stegun, Handbook of Mathematical Func-

tions with Formulas, Graphs, and Mathematical Tables, National Bureau of Standards, Applied Mathematics Series, no. 55, U. S. Government Printing Office, Washington, D. C., 1964.

In Table 7.3 for erfc $\sqrt{n \pi}$ the terminal digit should be increased by four units for $n=2$, by one unit for $n=5$, and decreased by one unit for $n=6$.

In Table 7.4 (Repeated Integrals of the Error Function) the terminal digit should be increased by one unit for $x=0.4, n=1$, and decreased by one unit for $x=1.1$, $n=11 ; x=1.2, n=2 ; x=1.2, n=6 ; x=1.3, n=5 ; x=1.3, n=11$.

W. G.

530.-JOSEPH KAYE, "A table of the first eleven repeated integrals of the error function," J. Math. Phys., v. 34, 1955, pp. 119-125.

In the entry for $x=.45, n=7$ the last digit should be decreased by one unit to read 0 instead of 1 .

W. G. 